\title{
Synthesis of silver nanoparticles using aqueous extracts of Pterodon emarginatus leaves collected in the summer and winter seasons
}

\author{
Giselle Zayra Silva Oliveira ${ }^{1,2} \cdot$ Cláudio Afonso Pinho Lopes $^{3} \cdot$ Marcelo Henrique Sousa $^{4} \cdot$ Luciano Paulino Silva $^{1,2}$
}

Received: 20 October 2017 / Accepted: 5 February 2019 / Published online: 4 March 2019

(c) The Author(s) 2019

\begin{abstract}
The aim of the present study was to evaluate the potential of silver nanoparticle synthesis using extracts from the leaves of Pterodon emarginatus (white sucupira) collected during the summer and winter seasons. Leaves were collected for the production of aqueous extracts, which were added to the aqueous solutions of silver nitrate leading to a final concentration of $1 \mathrm{mM}$. The reactions were incubated at $75^{\circ} \mathrm{C}$ for $150 \mathrm{~min}$ and monitored every $30 \mathrm{~min}$ by absorption spectroscopy at $425 \mathrm{~nm}$. The samples were complementarily characterized by dynamic light scattering, zeta potential, transmission electron microscopy, atomic force microscopy, MALDI-TOF mass spectrometry, Fourier transform infrared spectroscopy and X-ray diffraction analyses. Both extracts (summer and winter) exhibited a satisfactory reduction of silver ions, capable of inducing the formation of AgNPPe with considerable colloidal stability. The seasons of leaf collection interfered with the synthesis and yield of the AgNPPe, and also with their hydrodynamic diameters and zeta potentials, but the particles showed similar dry sizes (height and diameter), molecular profiles, and crystallinity patterns of the atoms. In sum, the results indicated that some AgNPPe parameters can be tunable by seasonal aspects of the plants and, therefore, such nanomaterials are propitious aiming future evaluation of their applications in several areas.
\end{abstract}

Keywords Cerrado $\cdot$ Fabaceae $\cdot$ Green chemistry $\cdot$ Metal nanoparticles

\section{Introduction}

Nowadays, the scientific revolution of nanotechnology has led to the development of several strategies for producing silver nanoparticles (AgNPs). In this scenario, green chemistry techniques are increasingly being consolidated using bioreducing agents and biological stabilizers (e.g., whole organisms or plant extracts, algae, mushrooms, yeasts, bacteria,

Luciano Paulino Silva

luciano.paulino@embrapa.br

1 Laboratory of Nanobiotechnology (LNANO), Embrapa Genetic Resources and Biotechnology, Brasilia, DF 70770-917, Brazil

2 Postgraduate Program in Nanoscience and Nanobiotechnology, Institute of Biological Sciences, University of Brasilia, Brasilia, DF 70910-900, Brazil

3 Laboratory of Electron Microscopy, Institute of Biological Sciences, University of Brasília, Brasilia, DF 70910-900, Brazil

4 Green Nanotechnology Group, Faculty of Ceilandia, University of Brasília, Brasilia, DF 72220-900, Brazil fungi and virus) of silver ions. Indeed, this is due to the fact that these materials comprise proteins, enzymes, amino acids, vitamins, lipids, nucleic acids and several secondary metabolites in their compositions that can act in the biosynthesis of AgNPs [1-4].

The option for this sustainable nanotechnological approach offers advantages such as simplicity to carry out, speed and low cost, which make it feasible and cost effective for several processes. Furthermore, it commonly involves a one-step process with biocompatible and non-toxic products, low concentrations of silver ions, mild reactive conditions and the use of water-soluble compounds. Hence, all these factors reduce the risk of toxicity to several living organisms and the environment $[5,6]$.

In this context, due to the rich Brazilian biodiversity, some studies in the literature related the use of endemic plants of the country for producing AgNPs [7-9]. However, there are no published reports mentioning the use of Pterodon emarginatus (white sucupira) leaf extracts for this purpose. This plant is typical of the Cerrado biome, and according to its taxonomic classification, it belongs to the Fabaceae (= Leguminosae) family and the Faboideae 
subfamily, which has four native species in Brazil: $P$. abruptus Benth, P. apparicioi Pedersoli, P. polygalaeflorus Benth and P. emarginatus Vogel [10].

In the phytochemical profile of $P$. emarginatus leaves, the major identified components are sesquiterpenes hydrocarbons [11], di-C-glycosylflavones, C,O-glycosylflavones, luteolin-7-O-rutinoside, saponins [12], steroids, pheophytin, flavonoids and other sesquiterpenic compounds [13], and all of them have the potential to contribute to the synthesis of AgNPs. Additionally, considering that several environmental factors may influence the availability of metabolites in plants [14], evaluating the effects of some of these factors on the synthesis of AgNPs is relevant for modulating the final properties. Thus, the aim of this study was to evaluate the potential of aqueous extracts from $P$. emarginatus (white sucupira) leaves collected in summer (rainy) and winter (dry) seasons in the reduction of silver ions and stabilizing AgNPs. Therefore, it is a pioneering work involving the synthesis of AgNPs using extracts from this plant as reducing agents.

\section{Materials and methods}

\section{Biological material collection}

P. emarginatus branches with leaves were collected and investigated under authorization for access to the genetic patrimony (CGEN n. 02001.007580/2014-95) from a private property in the municipality of Colinas do Sul-GO, Brazil $\left(14^{\circ} \mathrm{N}\right.$ and $\left.48^{\circ} \mathrm{W}\right)$ in early January and September, which correspond to the summer and winter seasons in the southern hemisphere, respectively. In the Cerrado biome, these periods are equivalent to rainy (mid) and dry (end) seasons, respectively. After collection, the leaves were stored at $-20{ }^{\circ} \mathrm{C}$ until used to prepare aqueous leaf extracts.

\section{Preparation of aqueous leaf extracts of $P$. emarginatus}

Before starting the preparation of the aqueous extracts, the leaves were washed with distilled water and then with ultrapure water (Milli-Q), and dried with paper towel. Next, each plant material was cut into small fragments (approximately $5 \times 5 \mathrm{~mm}$ ) and added to a beaker containing boiling ultrapure water (Milli-Q) (ratio 1:5 m/v), reaching a concentration of $200 \mathrm{mg} / \mathrm{mL}$ (crude leaves in water). This mixture was then put on a heating plate (model Q261, Quimis, Brazil) and boiled for 2 min. Subsequently, it was filtered using filter paper to obtain the aqueous leaf extract.

\section{Green synthesis of AgNPs using P. emarginatus aqueous leaf extracts}

For the synthesis of AgNPs with aqueous leaf extracts of $P$. emarginatus (AgNPPe), aqueous solutions of silver nitrate (final concentration $1 \mathrm{mM}=\sim 170 \mu \mathrm{g} / \mathrm{mL}$ ) were added to glass test tubes containing $P$. emarginatus aqueous leaf extracts at a ratio of $1: 1(\mathrm{v} / \mathrm{v})$, so that the extract produced according to "Preparation of aqueous leaf extracts of $P$. emarginatus" was $10 \%$ of the final volume of $30 \mathrm{~mL}$ of the reaction medium.

Subsequently, the reactants were incubated at $75{ }^{\circ} \mathrm{C}$ for 150 min in a water bath (Model Q334 M-24, Quimis, Brazil). Throughout this period, the changes in the reaction media color were monitored and the AgNPPe formation kinetics was evaluated with a UV-Vis spectrophotometer (Model Q898U, Quimis, Brazil) set at a wavelength of $425 \mathrm{~nm}$. In addition, spectrophotometric analyses (UV mini-1240, Shimadzu, Japan) were performed at the end of the reactions at wavelengths ranging from 350 to $550 \mathrm{~nm}$ with 10-nm intervals to achieve absorption curves of the samples.

\section{Dynamic light scattering (DLS) and surface zeta potential}

The use of DLS and zeta potential allowed obtaining hydrodynamic diameter values, polydispersity indexes (PdI) and zeta potential of AgNPPe after completing the syntheses. Moreover, identical analyses were also performed 14 days, 1 month, 2 months and 5 months after the synthesis reactions to monitor the stability of AgNPPe physical characteristics over time.

Thereunto, $100 \mu \mathrm{L}$ of the suspension of each sample and $900 \mu \mathrm{L}$ of ultrapure water (Milli-Q) were added to a cuvette (DTS 1070, Malvern, UK), which was then placed in the DLS-Zeta equipment (ZetaSizer Nano ZS, Malvern, UK), where the following operational criteria were applied: triplicate experiments, stabilization time of $120 \mathrm{~s}$ before measurements, temperature of $25^{\circ} \mathrm{C}$, spreading angle set at $173^{\circ}$ and automatic acquisitions (in relation to number and running time).

\section{Transmission electronic microscopy (TEM)}

Two microliters of AgNPPe samples was deposited on copper grids (Electron Microscopy Sciences, USA) coated with a thin layer of Formvar. After $12 \mathrm{~h}$ of drying under ambient conditions $\left(25^{\circ} \mathrm{C}\right)$, the samples were analyzed using a transmission electron microscope (JEM-1011, Jeol, 
Japan) operated at $100 \mathrm{kV}$. Electron photomicrographs were randomly obtained with a CCD camera (Gatan Ultrascan, USA) and AgNP diameters were measured using Image-Pro Plus software (Media Cybernetics, USA).

\section{Atomic force microscopy (AFM)}

To perform this analysis, $1 \mu \mathrm{L}$ of each AgNPPe sample was deposited on freshly cleaved muscovite mica surfaces and mounted on the top of a metal sample holder using doublesided adhesive tape. After drying, the samples were analyzed using a commercial atomic force microscope (SPM 9600, Shimadzu, Japan) operated with a silicon conical tip with a curvature radius of less than $10 \mathrm{~nm}$ and a rectangular cantilever with constant spring around $42 \mathrm{~N} / \mathrm{m}$. The images were acquired from randomly selected scanning areas of $10 \mu \mathrm{m} \times 10 \mu \mathrm{m}$ using dynamic operating mode, with phase acquisition mode at the scanning frequency of $1 \mathrm{~Hz}$ and resolution of $512 \times 512$ lines. After, the images were processed using offline SPM Manager 3.0 software (Shimadzu) and height distribution curves of the AgNPs were displayed with the Origin ${ }^{\circledR} 8$ software based on the average height parameter.

\section{Molecular profiles by MALDI-TOF mass spectrometry}

One microliter of the samples was mixed with $3 \mu \mathrm{L}$ of alpha-cyano-4-hydroxycinnamic acid matrix and applied to a MALDI-TOF target microplate (MSP96 Polished, Bruker Daltonics, Germany). Identifying compounds with $\mathrm{m} / \mathrm{z}$ 100-1000 was performed in triplicate using a MALDI-TOF mass spectrometer (AutoFlex Speed, Bruker Daltonics, Germany) operated in a positive-reflector mode with 5000 laser shots, 30-40\% laser intensity and external calibration using the main ions of the matrix (alpha-cyano-4-hydroxycinnamic acid) as a reference. FlexAnalysis 3.4 and MALDI Biotyper 3.1 programs were used to perform the spectral analyses and generate a dendrogram based on Euclidean distances, respectively.

\section{Fourier transform infrared spectroscopy (FTIR)}

To perform these analyses, approximately $1 \mathrm{mg}$ of the lyophilized samples (AgNPPe and their controls) was mixed with $100 \mathrm{mg}$ of potassium bromide ( $\mathrm{KBr})$, previously microwaved. Subsequently, for the formation of the pellets, these experimental samples were submitted to a hydraulic press under vacuum condition and controlled pressure (10 tons). The samples were then directed to the FTIR spectrophotometer (Vertex 70/70v, Bruker Optics, Germany) using a reading region with a waveband ranging between 400 and $4000 \mathrm{~cm}-1$ to obtain the spectra in the transmission percentage mode.

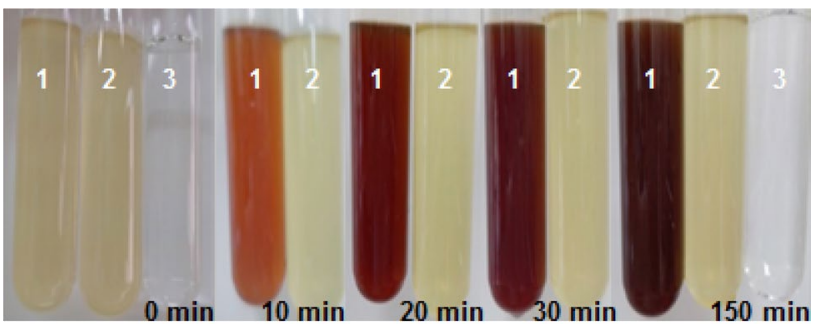

Fig. 1 Monitoring of the color changes in the reaction medium of the AgNP synthesis produced with aqueous extracts of $P$. emarginatus leaves collected during the summer. In this representation, 1 refers to AgNPs synthesized with $P$. emarginatus leaf extract at 10\%; 2 refers to a control composed of only aqueous extract at $10 \%$; and 3 to a control with only the silver nitrate solution at the final concentration of $1 \mathrm{mM}$

\section{X-ray diffraction (XRD)}

The acquisition of X-ray diffractograms from AgNPPe samples required a prior step of lyophilization. Next, the samples were deposited on the surface of a glass disk containing a thin layer of silicone grease, being necessary to ensure analyte fixation. The disk was transported to an X-ray diffractometer (Miniflex600, Rigaku, Japan) for analysis in the range of $2 \theta$ (degrees) varying from 30 to $90^{\circ}$ with a step of $0.05^{\circ}$ and step time of $5^{\circ}$ per min, using $\mathrm{Cu}-\mathrm{K} \alpha$ radiation $(\lambda=1.541 \AA)$ and operating at $40 \mathrm{kV}$ and $30 \mathrm{~mA}$.

\section{Statistical analyses}

Microsoft Office Excel 2010 software was used to calculate the means and standard deviation values of the data. The Past software was applied for statistical analyses [15], and the one-way ANOVA was adopted to analyze the variance, followed by the Tukey's test with a significance level set at 5\% $(P<0.05)$.

\section{Results and discussion}

\section{Color change of the reaction medium}

An assay was initially carried out to verify the potential of $P$. emarginatus aqueous leaf extract (collected in the summer) to reduce silver ions, based on color changes of the reaction media. It was found that the addition of $P$. emarginatus aqueous leaf extract solution at the concentration of $10 \%$ to silver nitrate solution (final concentration of $1 \mathrm{mM}$ ) induced changes in the reaction media color from light yellow to dark brown, indicating the formation of AgNPs during the $150 \mathrm{~min}$ of reaction. Such color transformations were similarly observed both in AgNPPe-Summer and AgNPPe-Winter (data not shown) syntheses, and can be exemplified by 
AgNPPe-Summer in Fig. 1. An explanation for these gradual and time-dependent color changes is related to the fact that excitation on the surface plasmon resonance (SPR) of the AgNPs promotes modifications in the color of suspensions during their reaction process and consequent formation [16].

\section{Formation kinetics and spectrophotometric absorption curves}

Preliminary optimization trials involving formation kinetics, DLS and surface zeta potential analyses also examined AgNPPe produced with $P$. emarginatus aqueous leaf extracts at $5 \%$ and $20 \%$ concentrations in the reaction media of the syntheses (data not shown). However, the most promising AgNPPe synthesis protocols (considering the intensity of absorbance) were those containing $10 \%$ of $P$. emarginatus aqueous leaf extract. It was also observed that among the time intervals assessed to monitor the formation of AgNPPeSummer and AgNPPe-Winter, both rapidly achieved the highest values of absorbance at $30 \mathrm{~min}$, followed by absorbance stabilization along the subsequent $120 \mathrm{~min}$, suggesting the maximum reduction of silver ions present in the reactions (Fig. 2a).

Figure $2 \mathrm{~b}$ allows to visualize the spectral bands around the wavelength of 400-425 nm, confirming the formation of AgNPPe, considering that Bindhu and Umadevin [17] have cited that this type of metallic nanoparticles exhibits a strong SPR absorption band in the 350-500 $\mathrm{nm}$ region. Regarding seasonal influence, it was verified that AgNPPe-Summer showed slightly higher yields in the synthesis process, as these particles had higher absorbance values than those observed for AgNPPe-Winter.

\section{Evaluation of colloidal stability by DLS and surface zeta potential analyses}

Although AgNPPe-Summer and AgNPPe-Winter showed similar PdI, these particles presented clearly distinct hydrodynamic diameters and surface charges. The Z-average values showed that the AgNPPe-Winter had hydrodynamic diameters $38.4 \%$ larger than the AgNPPe-Summer, while the average hydrodynamic diameter of particle population measurements evidenced that AgNPPe-Winter was present in two subpopulations, which were $47.5 \%$ and $7.5 \%$ smaller than AgNPPe-Summer (Table 1). In addition, according to the American Society for Testing and Materials (ASTM), the zeta potential values of $-33.3 \mathrm{mV}$ from AgNPPe-Summer and $-23.9 \mathrm{mV}$ from AgNPPe-Winter (Table 1) allow them to fall into different classes of colloidal suspension having properties of moderate stability and incipient instability, respectively [18].

Regarding the kinetic stability monitoring of the AgNPPe-Summer, significant increases of the hydrodynamic diameters were observed in the first 2 months after the synthesis when compared to newly synthesized AgNPPeSummer. On the other hand, no significant changes in PdI and zeta potential values were identified, indicating that these nanosystems did not tend to agglomerate even after 5 months of production. This fact points to a suitable colloidal stability and good homogeneity conditions. Regarding the kinetic monitoring of AgNPPe-Winter, a momentary

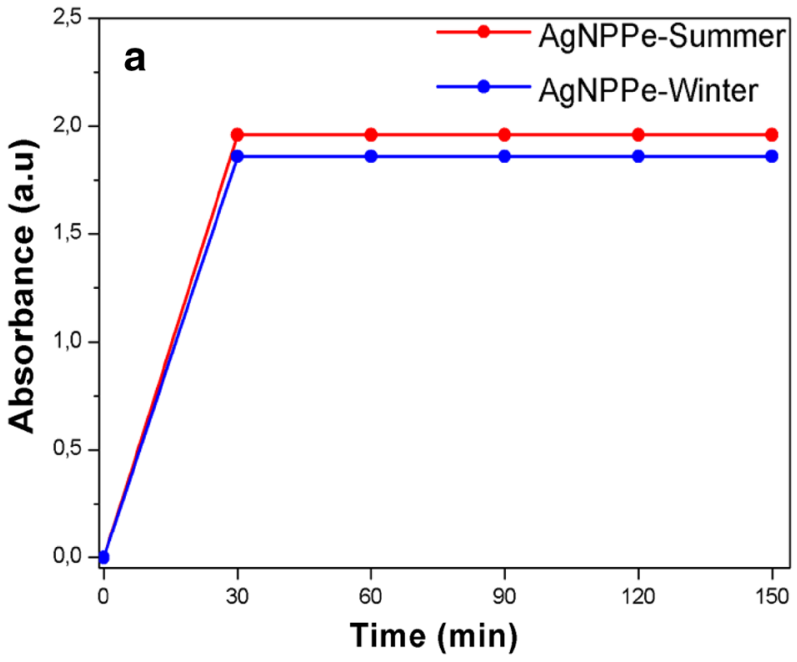

Fig. 2 Kinetic monitoring of AgNPPe formation by spectrophotometric analyses (425 nm) during $150 \mathrm{~min}$ (a) and AgNPPe spectrophotometric absorption curves and their respective controls (b). In these graphic representations, AgNPPe-Summer and AgNPPe-Winter refer to AgNPs synthesized with $P$. emarginatus aqueous extracts from

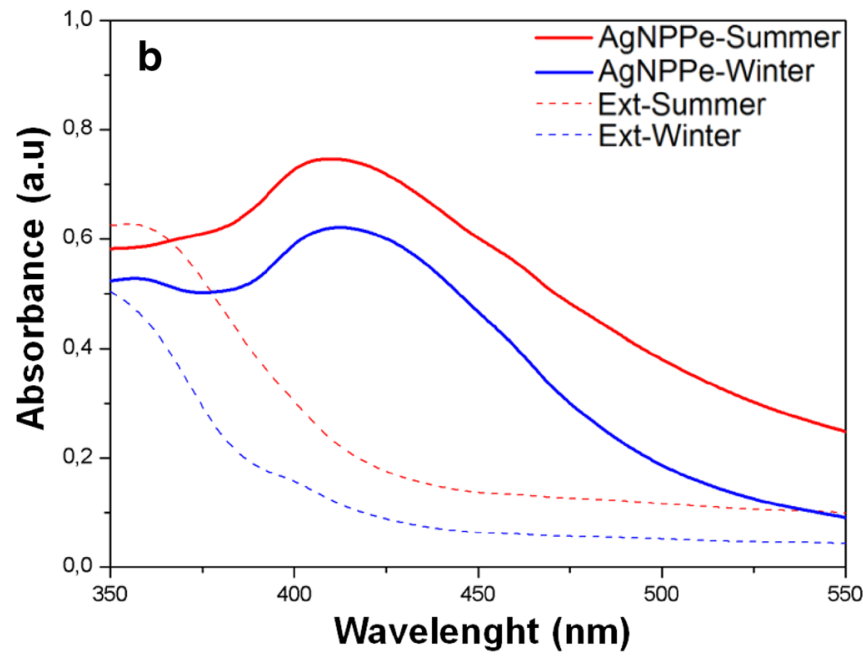

leaves collected during summer or winter seasons at a concentration of $10 \%$, respectively. Ext-Summer and Ext-Winter refer to $P$. emarginatus aqueous extracts from leaves collected in the summer and winter seasons at a concentration of $10 \%$, respectively 
Table 1 Dynamic light scattering (DLS) and surface zeta potential analyses of AgNPPe-Summer and AgNPPewinter

\begin{tabular}{llrll}
\hline Samples & $\begin{array}{l}\text { Average hydrodynamic diam- } \\
\text { eter of particle populations } \\
(\mathrm{nm})\end{array}$ & Z-average $(\mathrm{nm})$ & PdI & Zeta potential (mV) \\
\hline AgNPPe-Summer & $36.86 \pm 8.62$ & $66.58 \pm 1.63$ & $0.370 \pm 0.014$ & $-33.3 \pm 2.7$ \\
AgNPPe-Winter & $19.34 \pm 3.03$ and $34.09 \pm 10.28$ & $108.43 \pm 0.91$ & $0.372 \pm 0.012$ & $-23.9 \pm 0.5$ \\
\hline
\end{tabular}

Values represent mean \pm standard deviation of analyses obtained in triplicate
Table 2 Colloidal stability monitoring of AgNPPe-Summer and AgNPPe-Winter physical characteristics by dynamic light scattering (DLS) and surface zeta potential analyses

\begin{tabular}{lcll}
\hline $\begin{array}{l}\text { AgNPPe-sum- } \\
\text { mer }\end{array}$ & Z-average $(\mathrm{nm})$ & PdI & $\begin{array}{l}\text { Zeta potential } \\
(\mathrm{mV})\end{array}$ \\
\hline $\begin{array}{l}\text { Newly synthe- } \\
\text { sized }\end{array}$ & $66.58 \pm 1.63$ & $0.370 \pm 0.014$ & $-33.3 \pm 2.7$ \\
14 days & $62.71 \pm 1.00$ & $0.351 \pm 0.008$ & $-36.2 \pm 3.2$ \\
1 month & $71.89 \pm 0.93^{*}$ & $0.386 \pm 0.011$ & $-28.5 \pm 0.4$ \\
2 months & $74.63 \pm 3.63^{*}$ & $0.350 \pm 0.006$ & $-26.4 \pm 2.5$ \\
5 months & $68.72 \pm 1.20$ & $0.398 \pm 0.059$ & $-31.3 \pm 1.4$ \\
AgNPPe-winter & & & \\
Newly synthe- & $108.43 \pm 0.91$ & $0.372 \pm 0.012$ & $-23.9 \pm 0.5$ \\
$\quad$ sized & & & \\
14 days & $105.83 \pm 1.78$ & $0.364 \pm 0.015$ & $-22.0 \pm 0.7$ \\
1 month & $107.30 \pm 1.95$ & $0.357 \pm 0.008$ & $-22.7 \pm 1.0$ \\
2 months & $92.61 \pm 1.15^{*}$ & $0.252 \pm 0.007 *$ & $-23.9 \pm 0.8$ \\
5 months & $110.30 \pm 1.56$ & $0.339 \pm 0.007$ & $-22.2 \pm 0.5$ \\
\hline
\end{tabular}

Values represent mean \pm standard deviation of analyses obtained in triplicate. $* P<0.05$ when compared to the newly synthesized AgNPPe (one-way ANOVA followed by Turkey test)

decrease of hydrodynamic diameter and heterogeneity was evidenced after 2 months of the synthesis in comparison with the initial values (Table 2).

\section{Transmission electron microscopy (TEM) and atomic force microscopy (AFM)}

TEM imaging showed that AgNPPe-Summer and AgNPPeWinter had round shapes with smooth edges and dry diameters of $33.20 \pm 4.85 \mathrm{~nm}\left(r^{2}=0.97\right)$ and $28.10 \pm 6.20 \mathrm{~nm}$ $\left(r^{2}=0.96\right)$, respectively (Fig. 3a and b). Likewise, AFM analyses found that AgNPPe-Summer and AgNPPe-Winter share spherical shapes without the presence of agglomerates and with average heights of $33.96 \pm 5.20 \mathrm{~nm}\left(r^{2}=0.99\right)$ and $20.70 \pm 7.73 \mathrm{~nm}\left(r^{2}=0.92\right)$, respectively (Fig. $3 \mathrm{c}$ and d). There are several reports in the literature that corroborate for this typical format of AgNPs, as is the case of Rao and Tang [19], that by the use of TEM attested the spherical shape of AgNPs synthesized using Eriobotrya japonica leaf extract. Similarly, Gaddam and collaborators [20] verified, using AFM, the spherical shape of AgNPs synthesized from Cassia alata leaf extract.

By combining these two types of morphological information, it is possible to infer that any changes in the phytochemical profiles from seasonal environmental conditions (typical of summer and winter periods) did not expressively modify the formation process or the dry dimensions of AgNPPe.

\section{Molecular profiles assessed by MALDI-TOF mass spectrometry, FTIR analyses and crystallinity analyzed by X-ray diffraction (XRD)}

Figure 4a, b displays the mass spectra of the AgNPPe aqueous suspensions and their controls relative to the ions in the $\mathrm{m} / \mathrm{z}$ range from 100 to 1000 as choice criteria, while the dendrogram presented in Fig. 4c considered the abundance and intensity of the molecular components detected. From this, it was verified that the controls composed only by summer and winter $P$. emarginatus leaf extracts showed the highest similarity among the analyzed materials, and the same occurred between the AgNPPe-Summer and AgNPPe-Winter aqueous suspensions. Overall, it was observed that the extracts had molecular mass profiles different from those of AgNPPe independent of the season of leaf collection. This could be explained as a consequence of the oxidation process aiming the formation of AgNPs, in which the chemical transformation of some molecules certainly occurred, thus altering the presence or abundance of the ions (Fig. 4c). Similarly, the MALDI characterization of AgNPs biosynthesized with aqueous extracts of cashew nuts reveals that the AgNPs and their respective synthesizing extracts belong to clusters of different molecular mass profiles [21].

The qualitative analyses of the FTIR spectra were used to observe if between the spectral profiles of the AgNPPe and their respective controls there were changes provided by the functional groups of the biomolecules present in the plant extracts that may be involved in the formation (bioreduction of the silver ions) and in the overlapping of AgNPs. Thus, as shown in Fig. 4d, the spectral profiles of $P$. emarginatus extracts by FTIR reveal peaks and bands very similar to each other (with slight displacement), suggesting the same chemical bonds and clusters. So, in the extract of the leaves collected in the summer season, prominent peaks 


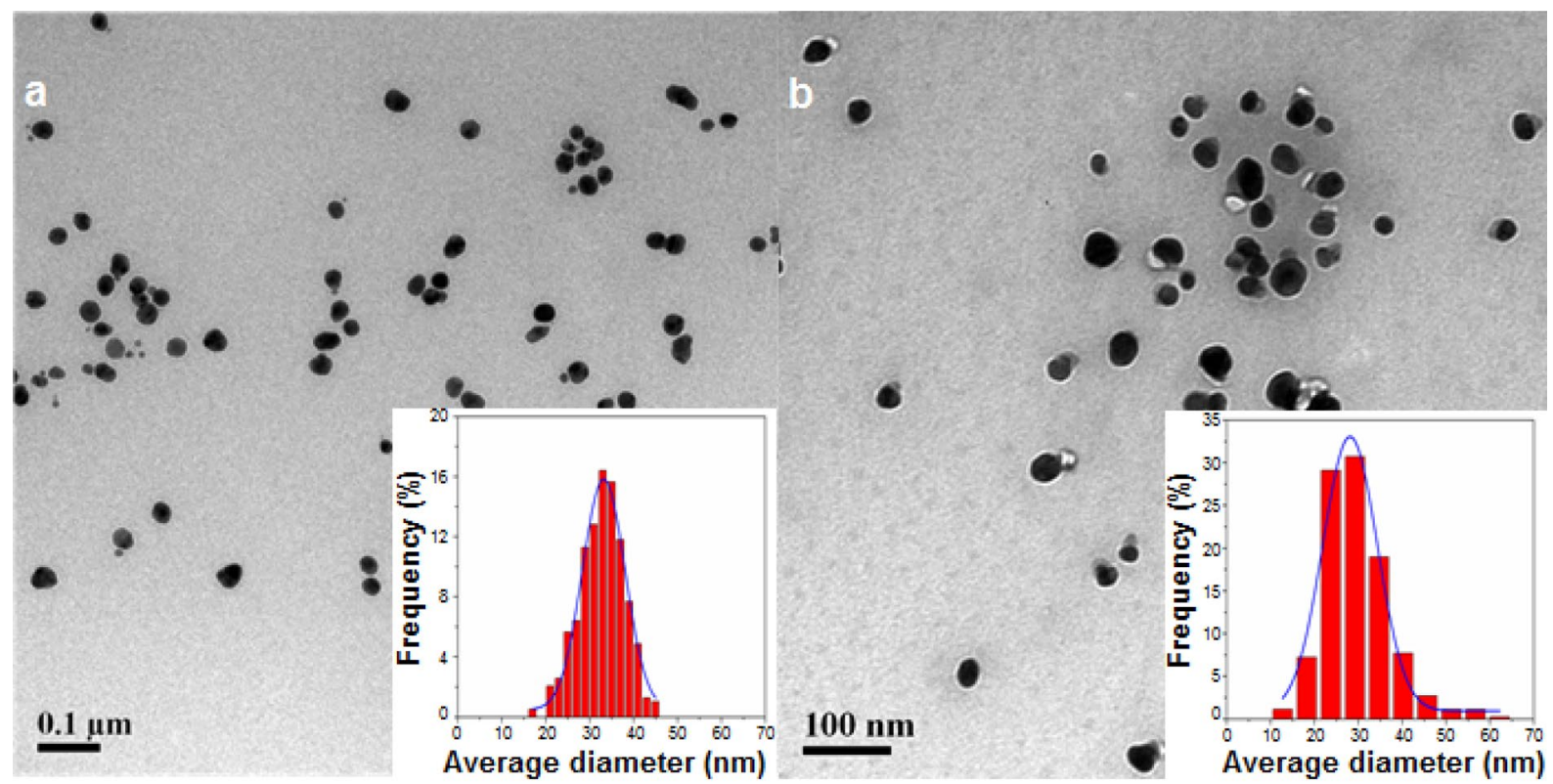

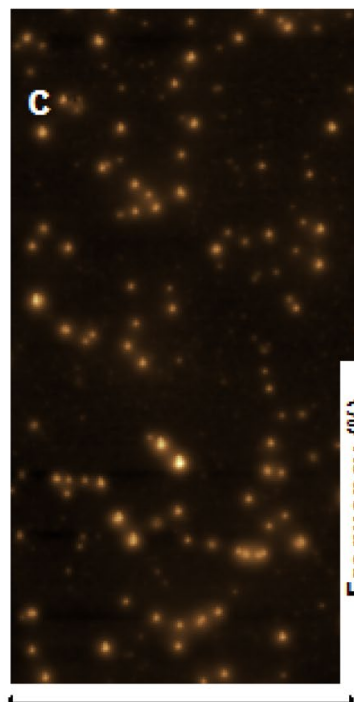

$5.00 \mathrm{um}$

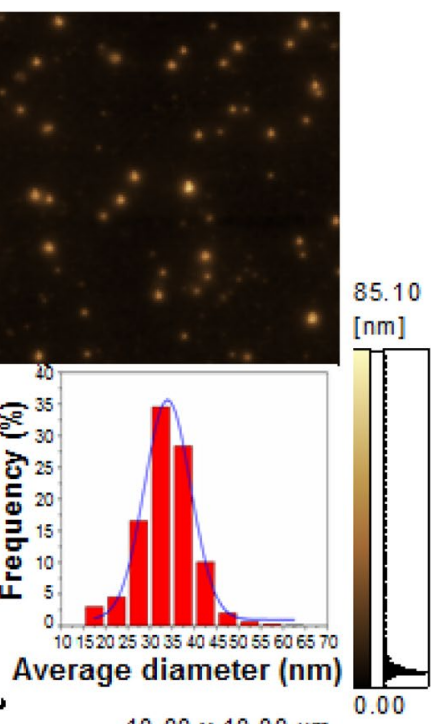

$10.00 \times 10.00 u m$

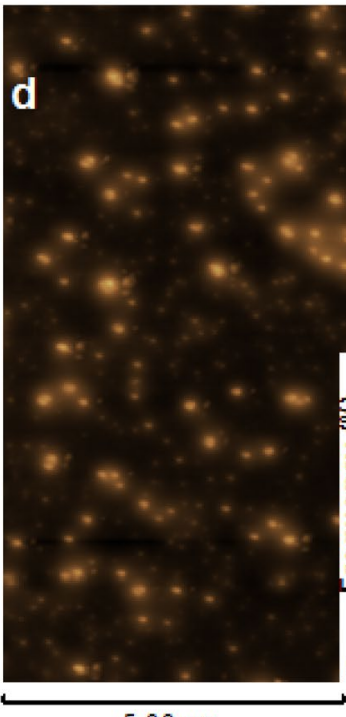

$5.00 \mathrm{um}$

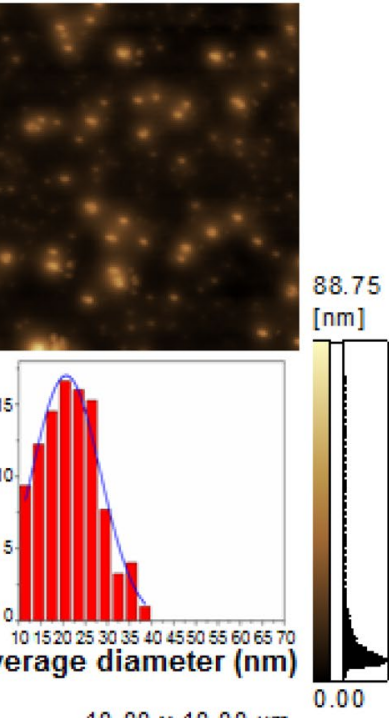

$10.00 \times 10.00 \mathrm{um}$

Fig. 3 TEM imaging and histograms for size class distribution of dry diameters of AgNPPe-Summer (a) and AgNPPe-Winter (b). AFM imaging and histograms for size class distribution of dry diameter (in height) of AgNPPe-Summer (c) and AgNPPe-Winter (d)

were observed in the region of 1626 and $1057 \mathrm{~cm}^{-1}$, while in the winter extract, the peaks were in the region of 1628 and $1072 \mathrm{~cm}^{-1}$. The presence of peaks in the regions of 1626 and $1628 \mathrm{~cm}-1$ can be attributed to the vibrations of the bonds of the amide functional group I [22, 23] or the carbonyl groups (1620-1636 $\left.\mathrm{cm}^{-1}\right)$, probably polyphenols [24], while peaks 1057 and $1072 \mathrm{~cm}^{-1}$ indicate C-O-type bonds, such as esters, ethers, alcohols or carboxylic acid [25].

In the AgNPPe-Summer and AgNPPe-Winter spectra, the same peaks identified in the respective extracts were observed. However, there was a differential peak at $1384 \mathrm{~cm}^{-1}$. This peak was also detected quite expressively in the spectrum of the silver nitrate solution, which in turn also showed a peak at $825 \mathrm{~cm}^{-1}$, which was suppressed in the NPs. The presence of the $1384 \mathrm{~cm}^{-1}$ peak in the silver nitrate solution is well characteristic of nitro groups, $-\mathrm{NO} 2$ $\left(1380-1300 \mathrm{~cm}^{-1}\right)$ [26]. The appearance in the AgNPPe samples indicates that the functional groups of some metabolites of the extracts were associated with free silver ions - $\mathrm{Ag}^{+}$, modifying the profile of bonds, possibly promoting the reduction in $\mathrm{Ag}^{\mathrm{O}}$.

Due to the similarity between the molecular profiles of AgNPs produced with extracts from leaves collected in different seasons, it was important to evaluate AgNPPe crystallinity by means of XRD analyses. As shown in Fig. 4e, diffraction peaks ascribed to the reflection of (111), (200), (220) and 

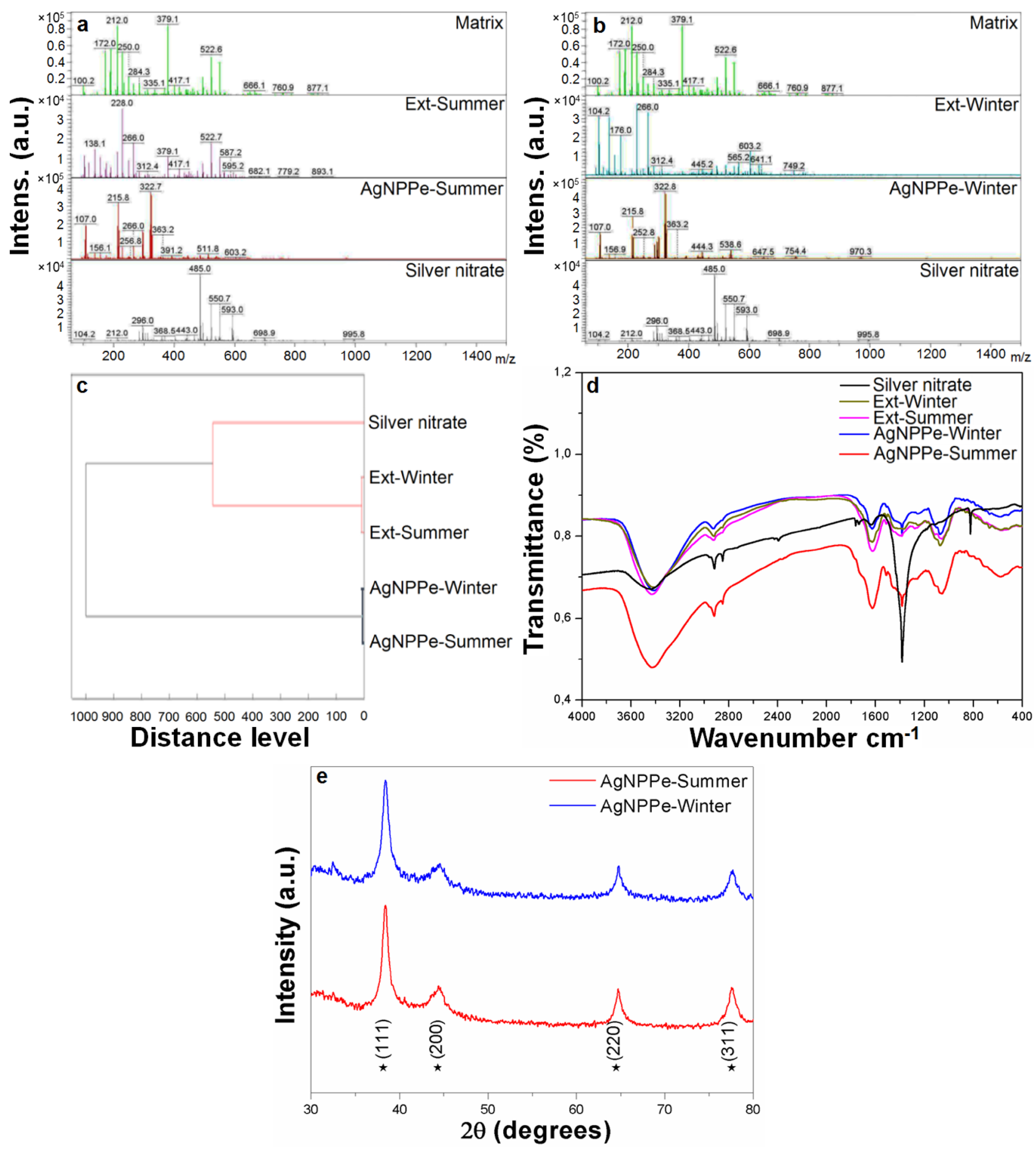

Fig. 4 Molecular mass profiles (a, b) and dendrogram (c) of AgNPPe and their controls obtained by mass spectrometry (MALDI-TOF MS). FTIR analyses of AgNPPe and their respective controls (d). AgNPPe X-ray diffractograms, stars-Fm-3 m cubic silver, JCPDS file no. 04-0783 (e). In these representations, AgNPPe-Summer and AgNPPe-Winter refer to AgNPs synthesized with P. emarginatus leaf extracts collected during summer and winter seasons at the concentration of $10 \%$, respectively. Ext-Summer and Ext-Winter refer to $P$. emarginatus aqueous extracts from leaves collected in the summer and winter seasons at a concentration of $10 \%$, respectively. Silver nitrate refers to aqueous solution of silver nitrate at a concentration of $1 \mathrm{mM}$ 
(311) planes and indexed to face-centered-cubic silver (JCPDS file no. 04-0783) could be observed in AgNPPe-Summer and AgNPPe-Winter samples. According to Anthony and collaborators [27], the absence of peaks from other phases indicates high purity of the synthesized products. Similarly, Dhand and collaborators [28] and Rónavári and collaborators [29] also reported this same pattern of crystallinity for AgNPs synthesized by green synthesis routes.

The lattice constants calculated from patterns, respectively, $4.083 \AA$ and $4.081 \AA$ for AgNPPe-Summer and AgNPPe-Winter samples are very analogous and consistent with the standard value $a=4.086 \AA$ from JCPDS file no. 04-0783. Additionally, the mean crystallite size of AgNPs was calculated using Scherrer's formula from the most intense diffraction peak (111), resulting in particles with average diameters of 10.9 and $10.4 \mathrm{~nm}$ for AgNPPe-Summer and AgNPPe-Winter samples, respectively. Since this is a calculation based on the crystallinity of the AgNP core, it is possible that the differences when compared to microscopic and DLS measurements are related to the distinguishable means of evaluating the samples and consequently differences in measurable patterns.

\section{Conclusion}

AgNPs synthesized using aqueous extracts of $P$. emarginatus (white sucupira) leaf collected in the summer and winter seasons differed in the yield of the AgNP synthesis process and also in hydrodynamic diameters and zeta potentials. Meantime, AgNPPe had similar dry dimensions (heights and diameters), molecular profiles and geometric organization patterns of the atoms. All this evidence indicates AgNPPe as promising nanoparticles for application in several areas of nanobiotechnology considering that the produced AgNPs have quite relatively similar properties even when biological material collection occurs in distinct seasons of the year.

Acknowledgements The authors of this study recognize the support and/or sponsorship of Coordenação de Aperfeiçoamento de Pessoal de Nível Superior (CAPES), Conselho Nacional de Desenvolvimento Científico e Tecnológico (CNPq), Fundação de Apoio à Pesquisa do Distrito Federal (FAPDF), Empresa Brasileira de Pesquisa Agropecuária (Embrapa) and Universidade de Brasília (UnB).

\section{Compliance with ethical standards}

Conflict of interests The authors have no conflict of interest to declare.

Open Access This article is distributed under the terms of the Creative Commons Attribution 4.0 International License (http://creativecommons.org/licenses/by/4.0/), which permits unrestricted use, distribution, and reproduction in any medium, provided you give appropriate credit to the original author(s) and the source, provide a link to the Creative Commons license, and indicate if changes were made.

\section{References}

1. Singh, P., Kim, Y.J., Zhang, D., Yang, D.C.: Biological synthesis of nanoparticles from plants and microorganisms. Trends Biotechnol. (2016). https://doi.org/10.1016/j.tibtech.2016.02.006

2. Al-Bahrani, R., Raman, J., Lakshmanan, H., Hassan, A.A., Sabaratnam, V.: Green synthesis of silver nanoparticles using tree oyster mushroom Pleurotus ostreatus and its inhibitory activity against pathogenic bactéria. Mater. Lett. (2017). https ://doi.org/10.1016/j.matlet.2016.09.069

3. Ovais, M., Khalil, A.T., Raza, A., Khan, M.A., Ahmad, I., Islam, N.U., Saravanan, M., Ubaid, M.F., Ali, M., Shinwari, Z.K.: Green synthesis of silver nanoparticles via plant extracts: beginning a new era in cancer theranostics. Nanomedicine $\mathbf{1 5}$ 85 (2016). https://doi.org/10.1016/j.matlet.2016.09.069

4. Chokshi, K., Pancha, I., Ghosh, T., Paliwal, C., Maurya, R., Ghosh, A., Mishra, S.: Green synthesis, characterization and antioxidant potential of silver nanoparticles biosynthesized from de-oiled biomass of thermotolerant oleaginous microalgae $\mathrm{Acu}$ todesmus dimorphus. RSC Adv. (2016). https://doi.org/10.1039/ c6ra15322d

5. Teimouri, M., Nejad, F.K., Attar, F., Saboury, A.A., Kostova, I., Benelli, G., Falahati, M.: Gold nanoparticles fabrication by plant extracts: synthesis, characterization, degradation of 4-nitrophenol from industrial wastewater, and insecticidal activity-a review. J. Clean Prod. (2018). https://doi.org/10.1016/j. jclepro.2018.02.268

6. Siddiqi, K.S., Husen, A., Rao, R.A.: A review on biosynthesis of silver nanoparticles and their biocidal properties. J. Nanobiotechnol. (2018). https://doi.org/10.1186/s12951-018-0334-5

7. Elemike, E.E., Onwudiwe, D.C., Ekennia, A.C., Ehiri, R.C., Nnaji, N.J.: Phytosynthesis of silver nanoparticles using aqueous leaf extracts of Lippia citriodora: antimicrobial, larvicidal and photocatalytic evaluations. Mater. Sci. Eng. C Mater. Biol. Appl. (2017). https://doi.org/10.1016/j.msec.2017.02.161

8. Soares, M.R., Corrêa, R.O., Stroppa, P.H.F., Marques, F.C., Andrade, G.F., Corrêa, C.C., Brandão, M.A.F., Raposo, N.R.: Biosynthesis of silver nanoparticles using Caesalpinia ferrea (Tul.) Martius extract: physicochemical characterization, antifungal activity and cytotoxicity. PeerJ (2018). https://doi.org/10.7717/ peerj. 4361

9. Edison, T.N.J.I., Atchudan, R., Sethuraman, M.G., Lee, Y.R.: Reductive-degradation of carcinogenic azo dyes using Anacardium occidentale testa derived silver nanoparticles. J. Photochem. Photobiol. B Biol. (2016). https://doi.org/10.1016/j.jphotobiol 2016.07.040

10. Carvalho, J.C.T.: Fitoterápicos Antiinflamatórios: Aspectos Químicos, Farmacológicos e Aplicações Terapêuticas. Tecmedd, Ribeirão Preto (2004)

11. Santos, A.P., Zatta, D.T., Moraes, W.F., Bara, M.T.F., Ferri, P.H., Silva, M.R.R., Paula, J.R.: Composição química, atividade antimicrobiana do óleo essencial e ocorrência de esteróides nas folhas de Pterodon emarginatus Vogel, Fabaceae. Rev. Bras. Farmacogn. (2010). https://doi.org/10.1590/s0102-695x2010005000052

12. Negri, G., Mattei, R., Mendes, F.R.: Antinociceptive activity of the HPLC- and MS-standardized hydroethanolic extract of Pterodon emarginatus Vogel leaves. Phytomed. (2014). https://doi. org/10.1016/j.phymed.2014.04.009

13. Miranda, M.L.D., Garcez, F.R., Abot, A.R., Garcez, W.S.: Sesquiterpenos e outros constituintes das folhas de Pterodon pubescens Benth (Leguminosae). Quim. Nova (2014). http://dx.doi. org/10.5935/0100-4042.20140065

14. Scognamiglio, M., D'abrosca, B., Esposito, A., Fiorentino, A.: Chemical composition and seasonality of aromatic mediterranean 
plant species by NMR-based metabolomics. J. Anal. Methods Chem. 15, 85 (2015). https://doi.org/10.1155/2015/258570

15. Hammer, Ø., Harper, D.A.T., Ryan, P.D.: PAST: paleontological statistics software for education and data analysis. Palaeontol. Electron. 4, 1-9 (2001)

16. Ahmed, M.J., Murtaza, G., Mehmood, A., Bhatti, T.M.: Green synthesis of silver nanoparticles using leaves extract of Skimmia laureola: characterization and antibacterial activity. Mater. Lett. (2015). https://doi.org/10.1016/j.matlet.2015.03.143

17. Bindhu, M.R., Umadevi, M.: Antibacterial and catalytic activities of green synthesized silver nanoparticles. Spectrochim. Acta A: Mol. Biomol. Spectrosc. 15, 35 (2015). https://doi.org/10.1016/j. saa.2014.07.045

18. ASTM: Standard test method for oil and grease and petroleum hydrocarbons in water. Am. Soc. Test Mat. 3921-3985 (1985)

19. Rao, B., Tang, R.C.: Green synthesis of silver nanoparticles with antibacterial activities using aqueous Eriobotrya japonica leaf extract. Adv. Nat. Sci. Nanosci. Nanotechnol. (2017). https://doi. org/10.1088/2043-6254/aa5983

20. Gaddam, S.A., Kotakadi, V.S., Godal, D.V.R.S., Rao, Y.S., Reddy, A.V.: Efficient and robust biofabrication of silver nanoparticles by cassia alata leaf extract and their antimicrobial activity. J. Nanostruct. Chem. 15, 85 (2014). https://doi.org/10.1007/s4009 7-014-0082-5

21. Bonatto, C.C., Silva, L.P.: Higher temperatures speed up the growth and control the size and optoelectrical properties of silver nanoparticles greenly synthesized by cashew nutshells. Ind. Crop Prod. (2014). https://doi.org/10.1016/j.indcrop.2014.04.007

22. Prakash, P., Gnanaprakasam, P., Emmanuel, R., Arokiyaraj, S., Saravanan, M.: Green synthesis of silver nanoparticles from leaf extract of Mimusops elengi, Linn. for enhanced antibacterial activity against multi drug resistant clinical isolates. Colloids Surf B Biointerfaces (2013). https://doi.org/10.1016/j.colsu rfb.2013.03.017

23. Beattie, D.A., Mensah, J.A., Beaussart, A., Franks, G.V., Yeap, K.Y.: In situ particle film ATR FTIR spectroscopy of poly
(N-isopropyl acrylamide) (PNIPAM) adsorption onto talc. Phys. Chem. Chem. Phys. (2014). https://doi.org/10.1039/c4cp03161j

24. Kumar, V., Yadav, S.C., Yadav, S.K.: Syzygium cumini leaf and seed extract mediated biosynthesis of silver nanoparticles and their characterization. J. Chem. Technol. Biotechnol. (2010). https ://doi.org/10.1002/jctb.2427

25. Tameme, H.J.A., Hameed, I.H., Idan, S.A., Hadi, M.Y.: Biochemical analysis of Origanum vulgare seeds by Fourier-transform infrared (FT-IR) spectroscopy and gas chromatography-mass spectrometry (GC-MS). J. Pharmacognosy Phytother. (2015). https://doi.org/10.5897/jpp2015.0362

26. Lopes, W.A., Fascio, M.: Esquema para interpretação de espectros de substâncias orgânicas na região do infravermelho. Quim. Nova (2004). https://doi.org/10.1590/S0100-40422004000400025

27. Anthony, K.J.P., Murugan, M., Jeyaraj, M., Rathinam, N.K., Sangiliyandi, G.: Synthesis of silver nanoparticles using pine mushroom extract: a potential antimicrobial agent against $E$. coli and $B$. subtilis. J. Ind. Eng. Chem. (2014). https://doi.org/10.1016/j. jiec.2013.10.008

28. Dhand, V., Soumya, L., Bharadwaj, S., Chakra, S., Bhatt, D., Sreedhar, B.: Green synthesis of silver nanoparticles using Coffea arabica seed extract and its antibacterial activity. Mater. Sci. Eng. C (2016). https://doi.org/10.1016/j.msec.2015.08.018

29. Rónavári, A., Kovács, D., Igaz, N., Vágvölgyi, C., Boros, I.M., Kónya, Z., Pfeiffer, I., Kiricsi, M.: Biological activity of greensynthesized silver nanoparticles depends on the applied natural extracts: a comprehensive study. Int. J. Nanomed. (2017). https:// doi.org/10.2147/ijn.s122842

Publisher's Note Springer Nature remains neutral with regard to jurisdictional claims in published maps and institutional affiliations. 